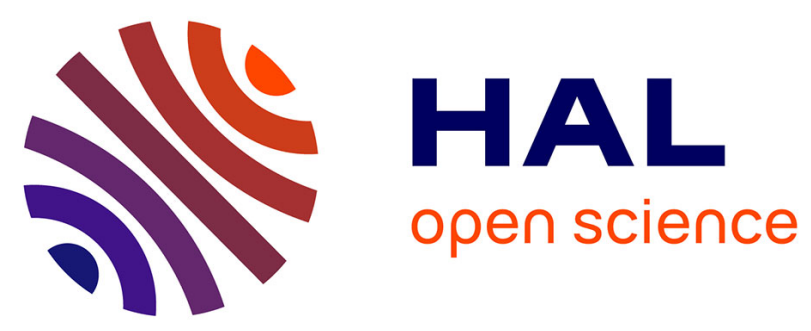

\title{
Biocompatible nanoparticles containing hydrophobic nickel-bis(dithiolene) complexes for NIR-mediated doxorubicin release and photothermal therapy
}

Mathieu Ciancone, Kenny Mebrouk, Nathalie Bellec, Catherine Le Goff-Gaillard, Yannick Arlot-Bonnemains, Thierry Benvegnu, Marc

Fourmigué, Franck Camerel, Sandrine Cammas-Marion

\section{To cite this version:}

Mathieu Ciancone, Kenny Mebrouk, Nathalie Bellec, Catherine Le Goff-Gaillard, Yannick ArlotBonnemains, et al.. Biocompatible nanoparticles containing hydrophobic nickel-bis(dithiolene) complexes for NIR-mediated doxorubicin release and photothermal therapy. Journal of materials chemistry B, 2018, 6 (12), pp.1744-1753. 10.1039/c7tb03289g . hal-01771086

\section{HAL Id: hal-01771086}

\author{
https://hal-univ-rennes1.archives-ouvertes.fr/hal-01771086
}

Submitted on 27 Apr 2018

HAL is a multi-disciplinary open access archive for the deposit and dissemination of scientific research documents, whether they are published or not. The documents may come from teaching and research institutions in France or abroad, or from public or private research centers.
L'archive ouverte pluridisciplinaire HAL, est destinée au dépôt et à la diffusion de documents scientifiques de niveau recherche, publiés ou non, émanant des établissements d'enseignement et de recherche français ou étrangers, des laboratoires publics ou privés. 


\title{
Biocompatible nanoparticles containing hydrophobic nickel-bis(dithiolene) complexes for NIR-mediated doxorubicin release and photothermal therapy
}

\author{
Mathieu Ciancone, ${ }^{\mathrm{a}}$ Kenny Mebrouk, ${ }^{\mathrm{a}}$ Nathalie Bellec, ${ }^{\mathrm{a}}$ Catherine Le Goff-Gaillard, ${ }^{\mathrm{b}}$ Yannick \\ Arlot-Bonnemains, ${ }^{\mathrm{b}}$ Thierry Benvegnu, ${ }^{\mathrm{a}}$ Marc Fourmigué, ${ }^{\mathrm{a}}$ Franck Camerel ${ }^{\mathrm{a},{ }^{*}}$ and Sandrine \\ Cammas-Marion, ${ }^{\mathrm{a}^{*}}$
}

a Univ Rennes, ENSCR, CNRS, ISCR (Institut des Sciences Chimiques de Rennes) - UMR 6226, $35000 \quad$ Rennes, $\quad$ France. Email: sandrine.marion.1@ensc-rennes.fr; franck.camerel@univ-rennes1.fr.

b Univ Rennes, CNRS, IGDR (Institut de Génétique et Développement de Rennes) - UMR 6290, BIOSIT - UMS 3480, Rennes, France.

* To whom correspondence should be sent.

Keywords: Biocompatible nanoparticles, Biodegradable block copolymers, Photothermal Controlled Drug Release, nickel-bis(dithiolene) complex, Photothermal therapy.

Abstract: Biocompatible nanoparticles (NPs) constituted by amphiphilic poly(ethylene glycol)block-poly(benzyl malate), PEG-b-PMLABe, have been designed for site-specific PhotoThermal Controlled Release (PTCR) of drug thanks to the presence of a Near Infra-Red (NIR) photothermally-active nickel-bis(dithiolene) complex in the inner core of NPs, together with Doxorubicin (Dox). Nanoprecipitation technique was used to prepare well-defined nickelbis(dithiolene) and nickel-bis(dithiolene)/Dox loaded NPs, which were characterized by dynamic light scattering (DLS), zeta-potential measurements and Transmission Electron Microscopy (TEM). We have shown that the Dox release was effectively controlled by NIR irradiation (long or pulsed NIR laser irradiation). Cytotoxicity experiments on HeLa and MDAMB-231 cells have shown that the incorporation of more than $10 \mathrm{w} \%$ of nickel-bis(dithiolene) complexes does not increase the intrinsic toxicity of the polymer nanoparticles. Finally, the viability of MDA-MB-231 cells was assessed after their incubation, for 24 hours, with empty NPs, Ni4C 12 loaded NPs, Dox loaded NPs or Ni4C 12 /Dox loaded NPs, without or with NIR irradiation. Above all, the results have highlighted that the $\mathrm{Ni}_{42}$ loaded NPs after 5 min NIR laser irradiation can induced strong cell death up to $80 \%$ at $50 \mu \mathrm{g} / \mathrm{mL}$. These results demonstrate that these NPs are good candidates for photothermal therapy. 


\section{Introduction}

To overcome the drawbacks associated to the administration of drugs, notably anti-cancer drugs, which are poorly water-soluble and lack of specific targeting towards malignant cells, tissues or organs, an alternative consists in encapsulating the drug into a nanocarrier [1]. In this context, the nanocarriers used as drug delivery systems are extremely diverse, ranging from inorganic porous materials to polymer-drug conjugates and nanoparticles [2-4]. Among those nanocarriers, nanoparticles (NPs) formed by amphiphilic block copolymers, also called polymeric micelles, have been, and continue to be, the subject of numerous researches as the result of their unique properties in aqueous solution [5-7]. Indeed, thanks to their amphiphilic nature, these block copolymers are able to self-assemble in aqueous solutions to form NPs with a hydrophilic corona protecting the nanocarrier from a rapid elimination by the immune system and a hydrophobic inner core allowing the encapsulation of hydrophobic or amphiphilic molecules [5-7].

Numerous amphiphilic block-copolymers have been designed to form polymeric micelles [57]. The hydrophilic block is mainly a poly(ethylene glycol), PEG, which is known to be biocompatible and approved by the US Food and Drug Administration (FDA) [8]. The PEG is associated with various hydrophobic blocks such as poly( $\varepsilon$-caprolactone), poly( $\beta$-benzyl Laspartate), poly(lactic-co-glycolic acid) and poly(lactic acid) [5-9].

The poly(malic acid), PMLA, and its derivatives constitute an interesting polymer family to develop block-copolymers able to form (bio)degradable and biocompatible nanocarriers [10]. Moreover, because both the synthesis of $\beta$-substituted $\beta$-lactones (monomers) and the anionic ring opening polymerization reaction are well-known and mastered, it is possible to obtain a large family of PMLA derivatives with properties adapted to the selected applications [10-15]. In this context, we have synthesized and characterized amphiphilic block-copolymers based on hydrophilic methoxy-PEG and hydrophobic PMLABe [12-15].

Besides the choice of the nature of the block-copolymer which has an influence on the nanoparticles properties in terms of diameter, stability, drug loading efficiency, etc., one has to design the nanocarriers in order that the drug release can be controlled under either internal (enzyme, pH, etc.) [16-19] or external (irradiation, magnetic or electrical fields, etc.) stimuli [20-22]. Among the molecules responding to an external stimulus, photothermal agents, more specifically the Near InfraRed (NIR) dyes, are considered as promising candidates for application in the field of controlled release. Indeed, they are able to absorb light in the NIR region, thus allowing to improve detection sensitivity, to increase image contrast, to decrease damages to healthy cells and tissues, and to have a deeper tissue penetration [23-37]. Their 
photothermal effect induces an accumulation of heat into the nanocarrier leading to a drug release. Various NIR dyes are used for the PhotoThermal Controlled Release (PTCR), among them the ones based on cyanine (IndoCyanine Green (ICG) and IR780) and porphyrin are often used [38]. These compounds have a high absorption in the NIR region and photothermal efficiency comparable to the one of gold nanostructures. However, their uses are limited due to their instability and their photobleaching upon laser irradiation as a result of the reaction between the NIR-dye and the singlet oxygen molecule $\left({ }^{1} \mathrm{O}_{2}\right)$, which is produced during the irradiation [39]. Moreover, this singlet oxygen molecule can affect the drug, thus leading to the release of an inactive form of the drug. Consequently, molecules which do not produce reactive oxygenated species (ROS) are privileged in order to allow an efficient photothermal effect together with a release of non-degraded drug. Photothermal molecules, which do not produce singlet oxygen under NIR irradiation, such as the Croconaine (Croc), have been designed [40]. But these low molar mass molecules still have several drawbacks such as a very short half-life in vivo [41]. In that respect, we have demonstrated that metal-bis(dithiolene) complexes display strong photothermal activity under NIR irradiation in solid-state, in gel and in solution [42-45]. These complexes are strong NIR absorbers with efficient photothermal properties. In addition, these complexes are photothermally and photochemically stable and do not produce singlet oxygen under NIR irradiation. Thus, they are good candidates for the photocontrolled release of drugs from organic nanocarriers under NIR irradiation [46]. Among them, we selected the [Ni(dphedt $\left.)_{2}\right]^{0}-\left(\mathrm{C}_{12} \mathrm{H}_{26}\right)_{4}$ complex, Ni4C 12 , carrying four long $\mathrm{C} 12$ carbon chains for its hydrophobic properties allowing its encapsulation into the hydrophobic inner-core of the nanoparticles based on PEG-b-PMLABe block copolymers [12]. Finally, we have selected the Doxorubicin (Dox) as an anti-cancer drug model to evaluate its release from the nanoparticles upon NIR irradiation.

In addition, we have very recently demonstrated that the proper functionalization of nickelbis(dithiolene) complexes with PEG chains has allowed good solubility in water. More importantly, in cellulo experiments have demonstrated that NIR-laser irradiation of cellular culture incubated with metal-bis(dithiolene) complexes can induce high level of cell death [45]. However, these complexes display non-negligible toxicity at high concentrations (Half maximal Inhibitory Concentration, $\mathrm{IC}_{50}$, around $500 \mu \mathrm{g} / \mathrm{mL}$ ). Thus, the encapsulation and the concentration of these complexes inside biocompatible nanocarriers can be a good way to decrease their toxicity toward the biological medium and to increase locally their photothermal activity. 
Therefore, we describe, within this paper, the synthesis and characterization of PEG- $b$ PMLABe based nanoparticles loaded with $\mathrm{Ni}_{42} \mathrm{C}_{12}$ complex or with $\mathrm{Ni}_{4} \mathrm{C}_{12}$ complex and Dox. The Dox release from nanoparticles was followed with and without long NIR laser irradiation as well as laser pulses. Finally, the in vitro cytotoxicity of empty nanoparticles, free Dox, $\mathrm{Ni}_{4} \mathrm{C}_{12}$ loaded nanoparticles, Dox loaded nanoparticles and $\mathrm{Ni}_{4} \mathrm{C}_{12}$ complex and Dox loaded nanoparticles was evaluated on two cell lines: the HeLa and MDA-MB-231 cells with and without laser irradiation.

\section{Experimental part}

Materials.

$\mathrm{PEG}_{46}-b$-PMLABe 77 block copolymers were synthesized as previously described [12]. Briefly, the benzyl malolactonate, monomer obtained in four steps starting from aspartic acid [47], was polymerized by anionic ring-opening polymerization in presence of tetraethylammonium salt of $\alpha$-methoxy, $\omega$-carboxylate PEG $_{46}$ as initiator. After purification, the block copolymers were characterized by proton NMR (structure and molar mass of the PMLABe block, Table 1) and size exclusion chromatography in THF (molar masses and dispersity, Table 1).

Nickel-bis(dithiolene) complexes $\mathrm{Ni}_{42} \mathrm{C}_{12}$ have been prepared as previously reported [48]. Briefly, 4,4'-bis(dodecanoxy)benzyl was sulfureted with $\mathrm{P}_{4} \mathrm{~S}_{10}$ in 1,3-dimethyl-2imidazolidinone (DMI), followed by hydrolysis of the intermediate phosphorous thioesters in the presence of the nickel salt such as $\mathrm{NiCl}_{2} \cdot 6 \mathrm{H}_{2} \mathrm{O}$ to afford directly the oxidized, neutral nickel complex. The compound was purified by column chromatography on silica gel and crystallized by slow evaporation dichloromethane from a $\mathrm{CH}_{2} \mathrm{Cl}_{2} / \mathrm{MeOH}$ mixture.

Doxorubicin and anhydrous THF were purchased from Sigma-Aldrich and used as received.

Methods.

$\mathrm{PEG}_{46}-b$-PMLABe 77 NPs preparation. Nanoparticles were prepared using the nanoprecipitation method described by Thioune et al. based on the self-assembly of hydrophobic or amphiphilic (co)polymer in aqueous medium [49]. To this end, the polymer is first solubilized in a watermiscible organic solvent, such as acetone or THF, and then rapidly added to an aqueous solution. The $\mathrm{PEG}_{46}-b-\mathrm{PMLABe}_{77}$ (5 mg) was thus solubilized in $1 \mathrm{~mL}$ of THF and rapidly added to $2 \mathrm{~mL}$ of ultrapure water under vigorous stirring. The mixture was then stirred at room temperature for $10 \mathrm{~min}$. In this process, the hydrophobic blocks of the copolymer (PMLABe) aggregate, leaving the hydrophilic blocks (PEG) in contact with the water, and leading to the formation of nanoparticles formed by the PEG $46-b$-PMLABe 77 block copolymers. The THF was 
then evaporated under reduced pressure (rotary evaporator) and the final volume was adjusted to $2 \mathrm{~mL}$ by addition of ultrapure water.

NPs[Ni4C 12 preparation. 5 mg of $\mathrm{PEG}_{46}-b$-PMLABe 77 were solubilized in $800 \mu \mathrm{L}$ of THF and $200 \mu \mathrm{l}$ of a solution of $\mathrm{Ni}_{4} \mathrm{C}_{12}$ in THF at a concentration of $2.5 \mathrm{mg} / \mathrm{mL}$ were then added, so that the amount of complex is $10 \%$ of mass of polymer ( $10 \%$ / polymer), i.e. $0.5 \mathrm{mg}$. This solution (polymer + complex in THF) was then rapidly added in $2 \mathrm{~mL}$ of ultrapure water under vigorous stirring. The mixture was stirred at room temperature for $10 \mathrm{~min}$, then the THF was evaporated under reduced pressure (rotary evaporator). The final volume was adjusted to $2 \mathrm{~mL}$ by addition of ultrapure water to give a brown solution of [ $\left.\mathrm{Ni}_{42} \mathrm{C}_{12}\right]$ loaded nanoparticles ([C] polymer $=2.5 \mathrm{mg} / \mathrm{mL},[\mathrm{C}]$ complex $=250 \mu \mathrm{g} / \mathrm{mL}$ ).

$\mathrm{NPs}[\mathrm{Dox}]$ preparation. A stock solution of Dox, $\mathrm{HCl}$ was first prepared in a THF/NEt $\mathrm{N}_{3}$ mixture (6 mL THF $+23 \mu \mathrm{L} \mathrm{NEt}_{3}$ ), as follow $10 \mathrm{mg}$ of Dox was solubilized in $4 \mathrm{~mL}$ of $\mathrm{THF} / \mathrm{NEt}_{3}$ $([$ Dox $]$ stock solution $=2.5 \mathrm{mg} / \mathrm{mL})$. Thereafter, $5 \mathrm{mg}$ of PEG $46-b-\mathrm{PMLABe}_{77}$ polymer were solubilized in $800 \mu \mathrm{L}$ of THF, and $200 \mu$ of the Dox solution ( $10 \%$ / polymer, ie $0.5 \mathrm{mg}$, initially introduced $=0.25 \mathrm{mg} / \mathrm{mL}$ ) are added. This solution (polymer + Dox in THF) was then rapidly added in $2 \mathrm{~mL}$ of ultrapure water under vigorous stirring. The mixture was stirred at room temperature for 10 minutes and then the THF was evaporated under reduced pressure (rotary evaporator). The final volume is adjusted to $2 \mathrm{~mL}$ by adding ultrapure water. The unloaded Dox was eliminated by centrifugation using a MicroCon system as follow: the orange solution was ultracentrifuged at 15,000 $\mathrm{g}$ for $7 \mathrm{~min}$ using a filter with an exclusion limit of 10,000 Da. Then, the filter was returned and centrifuged at 1,000 g for $1 \mathrm{~min}$. The concentrate was diluted with ultrapure water to obtain $2 \mathrm{~mL}$ of final solution. The Dox encapsulation efficiency was determined by measuring the absorbance of the Dox at $485 \mathrm{~nm}$ by UV-Vis spectroscopy. First, a calibration curve of free Dox in a water/DMF (20/80) mixture was realized as follows: 500 $\mu \mathrm{L}$ of the Dox stock solution in THF/NEt 3 was evaporated under reduced pressure. Then, $1 \mathrm{~mL}$ of water/DMF (20/80) was added. This concentrated solution ([Dox] $=1.25 \mathrm{mg} / \mathrm{mL})$ was diluted to obtain solutions with decreasing Dox concentration by adding the water/DMF mixture (20/80). The absorbance at $485 \mathrm{~nm}$ of the different samples of free Dox $(\mathrm{V}=400 \mu \mathrm{L})$ was then measured by UV-Vis spectroscopy. Once the calibration curve was realized (Figure S1), $80 \mu \mathrm{L}$ of the NPs[Dox] suspension were diluted with $320 \mu \mathrm{L}$ of DMF and its absorbance was measured at $485 \mathrm{~nm}$ by UV-Vis spectroscopy. This value was transformed into a concentration thanks to the calibration curve. Therefore, the concentration of encapsulated Dox 
was $108 \mu \mathrm{g} / \mathrm{mL}$, meaning that 22\% of the initially introduced Dox has been encapsulated (4\% relative to the polymer mass).

NPs[Ni4C 12 ,Dox $]$ preparation. 5 mg of PEG $_{46}-b-P_{\text {MLABe }}$ polymer were solubilized in 600 $\mu \mathrm{L}$ of THF, $200 \mu \mathrm{L}$ of the complex stock solution at a concentration of $2.5 \mathrm{mg} / \mathrm{mL}$ in THF $(10 \%$ / polymer, ie $0.5 \mathrm{mg}$ of $\left.\mathrm{Ni}_{4} \mathrm{C}_{12}\right)$ and $200 \mu \mathrm{l}$ of the Dox solution $(10 \%$ / polymer, ie $0.5 \mathrm{mg}$, initially introduced $=0.25 \mathrm{mg} / \mathrm{mL}$ ) are added. This solution (polymer + complex + Dox in THF) was then rapidly added in $2 \mathrm{~mL}$ of ultrapure water under vigorous stirring. The mixture was stirred at room temperature for 10 minutes and then the THF was evaporated under reduced pressure (rotary evaporator). The final volume is adjusted to $2 \mathrm{~mL}$ by adding ultrapure water. The unloaded Dox was eliminated by centrifugation using a MicroCon system as described above. The Dox encapsulation efficiency was determined by measuring the absorbance of the Dox at $485 \mathrm{~nm}$ by UV-Vis spectroscopy using a calibration curve of free Dox in a water/DMF (20/80) mixture realized as described above (Figure S1); then, $80 \mu \mathrm{L}$ of the NPs[Ni4C 12 ,Dox] suspension were diluted with $320 \mu \mathrm{L}$ of DMF and its absorbance was measured at $485 \mathrm{~nm}$ by UV-Vis spectroscopy. This value was transformed into a concentration thanks to the calibration curve. Therefore, the concentration of encapsulated Dox was $126 \mu \mathrm{g} / \mathrm{mL}$, meaning that $25 \%$ of the initially introduced Dox has been encapsulated (5\% relative to the polymer mass).

DLS experiments. The hydrodynamic diameters (Dh) and polydispersity indexes (PDI) of the prepared NPs were analyzed by dynamic light scattering (DLS) with a Zetasizer Nano-ZR90 (Malvern) apparatus at $25^{\circ} \mathrm{C}$ using a He6Ne laser at $633 \mathrm{~nm}$ and a detection angle of $90^{\circ}$.

TEM Measurements. TEM analyses of the NPs were realized at the "Institute des Sciences Chimiques de Rennes". Each sample $(5 \mu \mathrm{L})$ was deposited on a Formvar-carbon film coated on a copper grid (300 mesh). After 6 min, the excess of water was removed by absorption with filter paper and the sample was stained with phosphotungstic acid $(0.1 \mathrm{v} \%)$ for $30 \mathrm{~s}$. The grid was then placed under the electron beam. The microscope used was a JEOL 2010 LaB6 operating at $80 \mathrm{kV}$. The camera, on which the images were recorded, was a GATAN Orius 200D CCD (Charge Coupled Device) camera.

UV-vis-NIR titration. UV-Vis-NIR absorption spectra in solution were recorded on a Shimadzu UV3600 Plus spectrophotometer. Samples were placed in $1 \mathrm{~cm}$ path length quartz cuvettes. 
Photothermal studies. For the photothermal studies, $1 \mathrm{~mL}$ of NPs suspensions was irradiated through a quartz cuvette with a 940 nm-wavelength semiconductor laser (BWT Beijing LTD) for $10 \mathrm{~min}$. The power intensity of the laser could be adjusted externally $(0-10 \mathrm{~W})$. The output power was independently calibrated using an optical power meter. A thermocouple with an accuracy of $\pm 0.1^{\circ} \mathrm{C}$ connected to an Agilent U1253B multimeter was inserted into the solution. The thermocouple was inserted at such a position that the direct irradiation of the laser was avoided. The temperature was measured every $1 \mathrm{~s}$.

Measurement of Dox release from the NPs. The Dox release was directly studied in a quartz cuvette using a home-made dialysis system. For this, a dialysis membrane with a cut-off threshold of 3,500 Da was immersed in milliQ water for 30 minutes and then rinsed with clean water. The dialysis film was cut to the desired size and then placed on a $100 \mu \mathrm{L}$ Eppendorf tip of which has been cut to $2.9 \mathrm{~cm}$ from the top. The dialysis membrane was held on the tip with a plastic paraffin film (Parafilm). The system was then introduced into a quartz cuvette having a circular aperture and containing $2.7 \mathrm{~mL}$ of water. $150 \mu \mathrm{L}$ of the NPs suspension were then placed in the modified tip. The absorption spectra for the Dox release in water were recorded at room temperature using a Shimadzu UV3600 Plus spectrophotometer. For measurements under laser irradiation, the samples were irradiated at $5 \mathrm{~W} / \mathrm{cm}^{2}$ at $940 \mathrm{~nm}$ for a given time by the top of the quartz cuvette.

Cell culture. The HeLa and MDA-MB-231 cells were cultured in DMEM supplemented with $10 \%$ fetal bovine serum (FBS), $100 \mathrm{U} / \mathrm{mL}$ penicillin and $100 \mu \mathrm{g} / \mathrm{mL}$ streptomycin at $37^{\circ} \mathrm{C}$ in a humidified $5 \% \mathrm{CO}_{2}$ atmosphere.

In vitro evaluation of cytotoxicity. The effect of NPs on cell growth was assessed in 96 wells plates (MicrotestTM-96-Becton Dickinson). The cells were seeded at 2,500 cells per well of full medium (100 $\mu \mathrm{L} /$ well). The NPs suspensions at the appropriate concentration $(50,125,250$ $\mu \mathrm{g} / \mathrm{mL}$ ) were added 24 hours after seeding for further $24 \mathrm{~h}$. After exposure to the NPs, cell viability was determined using the MTT (thiazolyl-blue-tetrazolium-bromide, MTT from Sigma) assays [50]. In parallel, the effect of radiation was studied after the wells were irradiated with a $940 \mathrm{~nm}$ diode laser at $5 \mathrm{~W} / \mathrm{cm}^{2}$ for $5 \mathrm{~min}$ from the top. Then, the MTT tests were undertaken. The absorbance of the solutions was measured at wavelength of $570 \mathrm{~nm}$ using a BMG Labtech FLUOstar Optima plate reader. Triplicates were done for each group of treated cells 


\section{Results and Discussion}

Recently, we have demonstrated that the Ni-bis(dithiolene) complexes are promising photoactive agents for PTCR from liposomes under NIR irradiation, as a result of their good thermal and photo-stability, and their high photothermal activity [46]. To overcome the problems linked to the fast elimination in vivo of phospholipids, we proposed to encapsulate the hydrophobic derivatives of Ni-bis(dithiolene) into the inner-core of biocompatible nanoparticles constituted by the amphiphilic block copolymers $\mathrm{PEG}_{46}-b-\mathrm{PMLABe}_{77}$ (the number representing the number of monomer units in each block, i.e. 46 units of ethylene glycol (molar mass of PEG = 2,015 g/mol) and 77 units of MLABe (molar mass of PMLABe = 15,860 g/mol)). The PEG $46^{-}$ b-PMLABe 77 block copolymers used in this study were synthesized by anionic ring-opening polymerization of the benzyl malolactonate, MLABe, using an $\alpha$-methoxy, $\omega$-carboxylate PEG initiator, as described previously [12-15]. The molar mass of the PMLABe block was fixed by the ratio MLABe/PEG to a value of 77, corresponding to a theoretical PMLABe molar mass of 15,000 g/mol. After purifications, the PEG46-b-PMLABe 77 block copolymers were analyzed, as described previously [12], by ${ }^{1} \mathrm{H}$ NMR and Size Exclusion Chromatography (SEC); the NMR spectrum of the block copolymer allowed us to calculate the molar mass of the PMLABe block, knowing the one of the commercially available PEG block, while the SEC analysis gave access to the average molar mass and the dispersity (Table 1).

\begin{tabular}{|c|c|c|c|c|c|}
\hline $\begin{array}{c}\text { Theoretical } \\
\text { Molar Mass }\end{array}$ & $\begin{array}{c}\text { Given Molar } \\
\text { Mass } \\
\text { PMLABe }(\mathrm{g} / \mathrm{mol})^{\mathrm{a}}\end{array}$ & $\begin{array}{c}\text { Calculated Molar } \\
\text { PEG }(\mathrm{g} / \mathrm{mol})^{\mathrm{b}}\end{array}$ & $\begin{array}{c}\text { Molar Mass } \\
\text { PMLABe }(\mathrm{g} / \mathrm{mol})^{\mathrm{c}}\end{array}$ & $\begin{array}{c}\text { PEG- } b \text {-PMLABe } \\
(\mathrm{g} / \mathrm{mol})\end{array}$ & $\begin{array}{c}\text { Mw }(\mathrm{g} / \mathrm{mol})^{\mathrm{d}} \\
\mathrm{D}^{\mathrm{d}}\end{array}$ \\
\hline 15,000 & 2,015 & 15,860 & 17,880 & 5,460 & 1.38 \\
\hline
\end{tabular}

a. Determined by the ratio MLABe/initiator; b. PEG bought from PEG Iris Biotech; c. Molar mass calculated from ${ }^{1} \mathrm{H}$ NMR spectrum of the copolymer; $d$. Measured by SEC in THF $\left(1 \mathrm{ml} / \mathrm{min}, 40^{\circ} \mathrm{C}\right.$, Poly(styrene) standards).

Table 1. Characteristics of the PEG $46-b-P M L A B e_{77}$ block copolymer used in this study.

This $\mathrm{PEG}_{46}-b$-PMLABe 77 block copolymer allowed us to prepare the corresponding nanoparticles (NPs) using the nanoprecipitation method, initially described by Thioune et al. [49]. The block-copolymer, the $\mathrm{Ni}_{4} \mathrm{C}_{12}$ and the Dox are dissolved in an organic solvent miscible with water, in our study THF, and this solution is rapidly added to water under vigorous stirring. 
As a result of their nature, the block-copolymer chains are able to immediately self-assemble leading to the formation of well-defined nanoparticles, after evaporation of THF under reduced pressure. When the nanoprecipitation is realized in presence of $\mathrm{Ni}_{4} \mathrm{C}_{12}$, Dox or $\mathrm{Ni}_{42} \mathrm{C}_{12} / \mathrm{Dox}$, these non-encapsulated molecules were eliminated by ultracentrifugation/filtration using Microcon system. The solution contained in the Microcon, after ultracentrifugation, was kept and correctly diluted. The empty, Dox, $\mathrm{Ni}_{4} \mathrm{C}_{12}$ and $\mathrm{Ni}_{4} \mathrm{C}_{12} /$ Dox loaded nanoparticles were then characterized by dynamic light scattering (DLS), and zetametry. The two analytical methods give access to the hydrodynamic diameter, polydispersity and surface charge of the nanoparticles. The amount of encapsulated $\mathrm{Ni}_{42}$ and Dox was evaluated using UV analysis. The characteristics of the obtained NPs are gathered in Table 2.

\begin{tabular}{|c|c|c|c|c|c|}
\hline & \multicolumn{2}{|l|}{$\mathrm{DLS}^{\mathrm{a}}$} & \multirow{2}{*}{ Zetametry $(\mathrm{mV})^{\mathrm{a}}$} & \multirow{2}{*}{ wt $\% N i 4 C_{12}{ }^{b}$} & \multirow{2}{*}{$w t \% D^{c}{ }^{c}$} \\
\hline & Average diameter (nm) & Dispersity & & & \\
\hline Empty NPs & 90 & 0.14 & -25 & -- & -- \\
\hline NPs[Dox] & 80 & 0.24 & -24 & -- & 4 \\
\hline $\mathrm{NPs}\left[\mathrm{Ni}_{4} \mathrm{C}_{12}\right]$ & 110 & 0.18 & -27 & 10 & -- \\
\hline $\mathrm{NPs}\left[\mathrm{Ni}_{4} \mathrm{C}_{12}, \mathrm{Dox}\right]$ & 100 & 0.22 & -26 & 10 & 5 \\
\hline
\end{tabular}

a. Measurements realized on a Nanosizer Nano-ZR90 (Malvern); b. Confirmed by UV-vis-NIR absorption measurements performed on the filtrate; c. Determined by UV at 485nm using a standard curve established with Dox solutions with various concentrations.

Table 2. Characteristics of empty, Dox, Ni4C 12 and Ni4C $C_{12} /$ Dox loaded NPs.

DLS measurements confirmed the formation of nano-objects with an average size of about 100 $\mathrm{nm}$ and a quite narrow dispersity of around 0.1-0.2 (Table 2). Due to the encapsulation of $\mathrm{Ni}_{4} \mathrm{C}_{12}$ complex, the diameter of the $\mathrm{NPs}\left[\mathrm{Ni}_{4} \mathrm{C}_{12}\right]$ is greater $(110 \mathrm{~nm})$ than that of the empty polymeric nanoparticles $\left(90 \mathrm{~nm}\right.$ ) (Figure S2-S3). The dispersity of the NPs[Ni4C $\left.\mathrm{C}_{12}\right](0.18)$ and the negative zeta potential $(-27 \mathrm{mV})$ indicate that the nanoparticles are homogeneous and do not form any aggregate in solution. DLS measurements performed on the NPs[Dox] and the $\mathrm{NPs}\left[\mathrm{Ni}_{4} \mathrm{C}_{12}\right.$,Dox $]$ suspensions show that the encapsulation of the Dox has little influence on the final size of the nanoparticles (Figure S4).

UV-Vis-NIR absorption measurements have revealed that using $10 \mathrm{wt} \%$ of complex /polymer, all the complex is encapsulated inside the nanoparticles. In fact, no NIR signal has been detected in the filtrate (Figure S5). The $\mathrm{Ni}_{12}$ complex encapsulated in $\mathrm{PEG}_{46}-b-\mathrm{PMLABe}_{77} \mathrm{NPs}$ (NPs[Ni4C 12$]$ ) and suspended in water has an absorption maximum at $914 \mathrm{~nm}$ and a molar 
absorption coefficient of about 10,200 L/mol/cm. It should be noted that these values are lower than that of the free $\mathrm{Ni}_{12}$ complex in solution in dichloromethane $(\lambda \max =933 \mathrm{~nm}$ and $\varepsilon=$ 31,300 L/mol/cm). Attempts have been made to increase the amount of encapsulated complex. Introduction of $50 \mathrm{wt} \%$ of complex has been tried in the polymer NPs (50 wt\% complex/polymer). However, only $13 w t \%$ of the $\mathrm{Ni} 4 \mathrm{C}_{12}$ polymer was efficiently encapsulated as revealed by UV-vis-NIR measurements performed on the aqueous suspension. Due to the insolubility of the complex in water, the excess product remains adhered to the walls of the round-bottom flask during preparation. Moreover, the DLS measurements reveal the presence of large nanoparticles with a size of $240 \mathrm{~nm}$. This increase in size is probably due to the presence of nano-aggregates of non-encapsulated $\mathrm{Ni}_{4} \mathrm{C}_{12}$ in the suspension of $\mathrm{NPs}\left[\mathrm{Ni}_{4} \mathrm{C}_{12}\right]$. Therefore, it can be concluded that a maximum of $13 \mathrm{wt} \%$ of $\mathrm{Ni}_{42} \mathrm{C}_{12}$ complex can be incorporated in the polymeric nanovectors and thus the use of $10 \mathrm{wt} \% \mathrm{Ni}_{12}$ /polymer is a good compromise for PTCR applications and photothermal therapy. UV-Vis-NIR measurements have also revealed that $25 \mathrm{wt} \%$ of the initially introduced Dox has been encapsulated, evaluated to $5 \mathrm{wt} \%$ relative to the polymer mass.

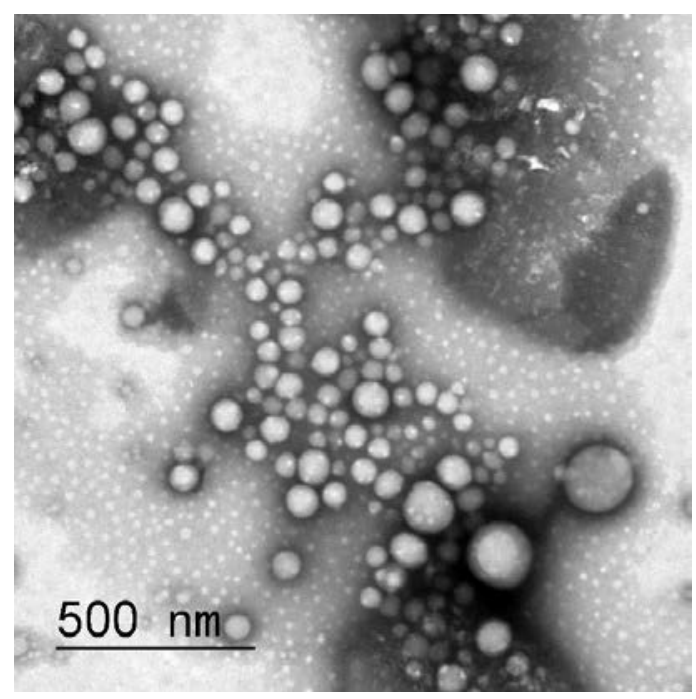

Figure 1. Image obtained by TEM of the NPs[Ni4C 12 ] using a Jeol 2010 LaB6 apparatus operating under a voltage of $80 \mathrm{KeV}$. The sample was previously stained with $0.1 \mathrm{v} \%$ of phosphotungstic acid.

The empty and $\mathrm{Ni}_{4} \mathrm{C}_{12}$ loaded NPs were analyzed by transmission electron microscopy, Figure S6 and Figure 1, respectively. As shown by Figures 1 and S6, both the empty and Ni4C 12 loaded 
nanoparticles have a spherical shape. The images show a quite large size repartition with an average diameter of $60 \mathrm{~nm}$ with several small NPs and few larger ones. The average diameter measured by TEM is lower than the one measured by DLS because the hydration layer is not visible by TEM.

One important evaluated parameter is the stability of Ni4C 12 loaded PEG $46-b$-PMLABe 77 NPs. For that, we have followed the evolution of the NPs diameter with time by DLS measurements (Figure 2a). As shown in Figure 2a, the average diameter remained stable at around $110 \mathrm{~nm}$ over three months, highlighting a good stability of the NPs in aqueous solution. Moreover, we have irradiated the solution containing the $\mathrm{NPs}\left[\mathrm{Ni}_{4} \mathrm{C}_{12}\right]$ after 86 days in suspension (Figure 2a). Suspensions of $\mathrm{NPs}\left[\mathrm{Ni}_{42} \mathrm{C}_{12}\right]$ have also been irradiated following several irradiation cycle given in Figure 2b. Irradiation has been performed with a 940-nm laser wavelength which is close to the absorption maxima of the $\mathrm{Ni}_{12} \mathrm{C}_{12}$ complex in the NIR region (Figure S5). Several conclusions can be drawn from the results presented in Figure 2.

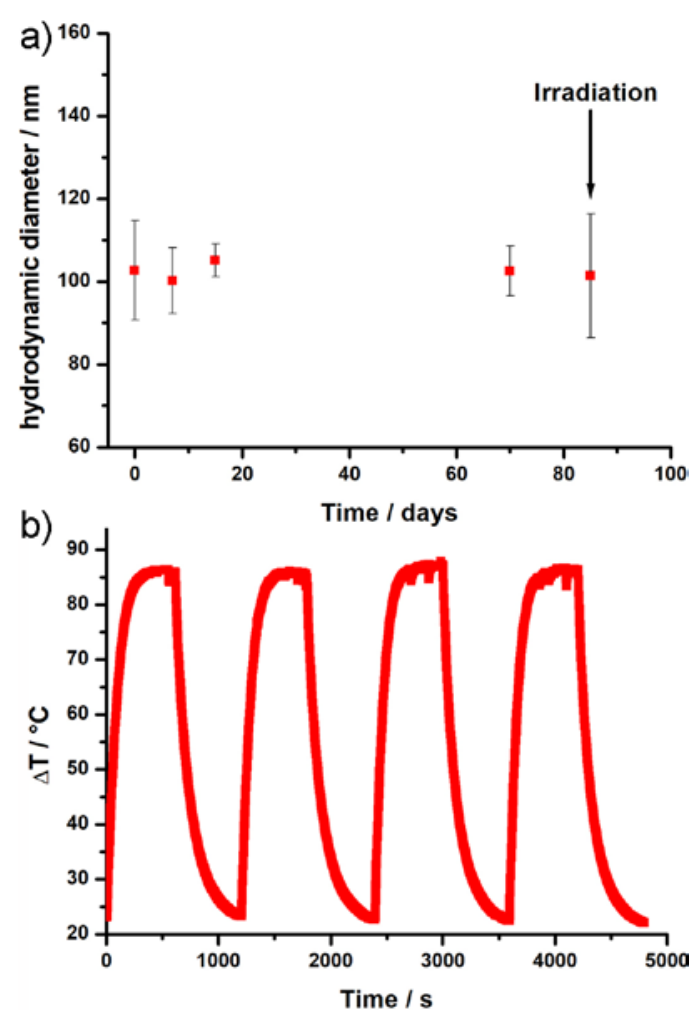

Figure 2. a. Evolution of the average diameter of $\mathrm{NPs}\left[\mathrm{Ni}_{4} \mathrm{C}_{12}\right]$ in water as a function of time $(C=2.5 \mathrm{mg} / \mathrm{mL})$. After 86 days, identical hydrodynamic diameters has been measured before and after laser irradiation (940 nm, $10 \mathrm{~min}, 5 \mathrm{~W} / \mathrm{cm}^{2}$ ) (error bars have been determined on

three different batches); $\boldsymbol{b}$. Measurement of the temperature rise of a suspension of $\mathrm{NPs}\left[\mathrm{Ni}_{42} \mathrm{C}_{12}\right]$ in water as a function of time and under laser irradiation $(C=2.5 \mathrm{mg} / \mathrm{mL}$ of 
nanoparticles, $C=0.25 \mathrm{mg} / \mathrm{mL}$ of $\mathrm{Ni}_{4} \mathrm{C}_{12}$ complex), $940 \mathrm{~nm}, 5 \mathrm{~W} / \mathrm{cm}^{2}, 10 \mathrm{~min}$ ON and $10 \mathrm{~min}$ OFF, 4 cycles).

First, we observed that the average diameter of the $\mathrm{NPs}\left[\mathrm{Ni}_{4} \mathrm{C}_{12}\right]$ before and after irradiation (Figure 2a) remains unchanged (110 nm), highlighting the stability of the nanoparticles under NIR irradiation. TEM experiments performed after irradiation have confirmed that the morphology of the NPs is not affected by the laser irradiation (Figure S7). UV-vis-NIR experiments have also revealed that the complex is not degraded during the irradiation (Figure S8). Second, these results highlight the photothermal effect of the $\mathrm{NPs}\left[\mathrm{Ni}_{4} \mathrm{C}_{12}\right]$ with a temperature increase of more than $85^{\circ} \mathrm{C}$. It should be also noted that this photothermal effect is constant and reproducible even after several irradiation cycles. Moreover, the NIR irradiation of pure water and empty NPs suspension only lead to a moderated increase of temperature $\left(+15^{\circ} \mathrm{C}\right)$, while the irradiation of a $\mathrm{Ni}_{4} \mathrm{C}_{12}$ loaded NPs suspension induces a drastic increase in temperature of about $75^{\circ} \mathrm{C}$ (Figure S9). Therefore, the strong photothermal property of $\mathrm{NPs}\left[\mathrm{Ni}_{4} \mathrm{C}_{12}\right]$ is a result of the presence of $\mathrm{Ni}_{4} \mathrm{C}_{12}$ within the NPs inner core. Finally, the photothermal efficiency $(\eta)$ of the $\mathrm{NPs}\left[\mathrm{Ni}_{4} \mathrm{C}_{12}\right]$ was determined using the equation given by Roper et al. [50] (Figure S10): the calculated $\eta$ has a value of $26 \%$. Such value is higher than the one calculated for liposomes encapsulating, in its inner aqueous core, another PEGylated nickel-bis(dithiolene) complex [46], probably due the encapsulation in the hydrophobic core which prevents deactivation by the surrounding water molecules.

In conclusion, all these results highlighted that the $\mathrm{PEG}_{46}-b-\mathrm{PMLABe}_{77}$ based NPs encapsulating the complex $\mathrm{Ni}_{42} \mathrm{C}_{12}$ were stable both in time and under laser irradiation, together with a good photothermal efficiency.

The Dox release from NPs[Ni4C 12 ,Dox] upon NIR-irradiation was evaluated by dialysis with and without laser irradiation at $940 \mathrm{~nm}$. The absorbance of the out-side solution containing the released Dox was measured regularly by UV at $485 \mathrm{~nm}$. As shown by Figure 3, several experiments were realized: Dox release without NIR irradiation, Dox release after a prolonged NIR irradiation of $15 \mathrm{~min}$ at $\mathrm{T}_{0}$ and a NIR irradiation of 2 min every $30 \mathrm{~min}$. The percent of Dox released with time was calculated using the Equation 1:

$$
\% \text { of released Dox }=\frac{A t-A 0}{A f} * 100
$$

Where At: absorbance measured at $t, A 0:$ absorbance measured at $t=0$ and Af: absorbance measured at the end of the experiment by adding a drop of DMF to break the NPs and release the Dox still encapsulated.

Equation 1. Calculation of Dox release from the absorbance measured by UV at $485 \mathrm{~nm}$. 
On Figure 3a, the amount of Dox released from the NPs[Ni4C $\mathrm{C}_{12}$,Dox] without NIR irradiation was lower than 5\%, while upon 15 min of NIR irradiation at the beginning of the release process more than $30 \%$ of Dox were released after 30 min. However after 18 hours of incubation, no more Dox was released from the nanocarrier, probably as a result of the low solubility of Dox in aqueous medium preventing its diffusion outside the polymer network constituting the NPs or by a higher affinity of the Dox for the hydrophobic PMLABe inner core. Nevertheless, this experiment has highlighted that the NIR irradiation induces a larger and faster Dox release from the NPs, probably because of a change in the NPs permeability resulting from the temperature increase due to the irradiation of the NIR-sensitive dye.
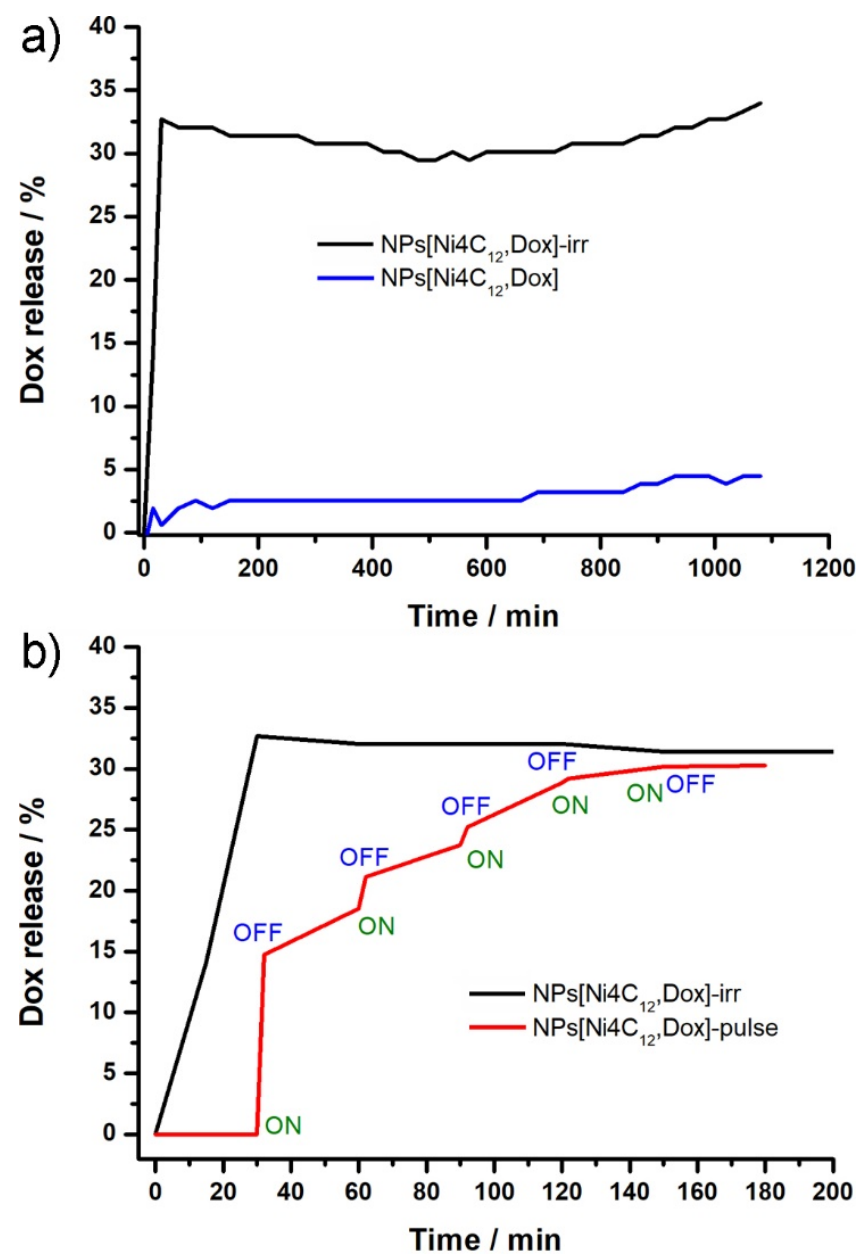

Figure 3. Dox release (\%) as a function of time from a solution of $P E G_{46}-b-P M L A B e_{77}$ based NPs containing Dox and Ni4C 12 : a. without and with a NIR irradiation $\left(940 \mathrm{~nm}, 5 \mathrm{~W} / \mathrm{cm}^{2}, 15\right.$ min at the beginning); $b$. with an initial $15 \mathrm{~min}$ NIR irradiation (940 nm, $5 \mathrm{~W} / \mathrm{cm}^{2}, 15 \mathrm{~min}$ ) or with several intermittent NIR irradiations (940 nm, $5 \mathrm{~W} / \mathrm{cm}^{2}, 2 \mathrm{~min}$ ON, $30 \mathrm{~min}$ OFF). 
More interestingly, additional experiments were realized with a sequential NIR irradiation of the NPs[Ni4C 12 ,Dox] suspension (Figure 3b). As shown by the graph of Figure 3b, 15\% of Dox was released after the first NIR irradiation. When the NIR irradiation was stopped, the Dox release slowed down and accelerated again during the next step of NIR irradiation until the plateau at 30\% of Dox release is reached. At that time, the effect of NIR irradiation is minor. The maximum Dox release is achieved, in this case, after 3 hours in suspension. The exposition of NPs to the laser light probably increases definitively their permeability. Indeed, a slow Dox release is observed during the period without NIR irradiation, release which is, moreover, faster than the one observed for the NPs[Ni4C 12 ,Dox $]$ not submitted to NIR irradiation. It should be noticed that UV-vis-NIR titration performed on the dialysate after irradiation did not shown absorption in the NIR region, meaning that this hydrophobic $\mathrm{Ni}_{42} \mathrm{C}_{12}$ nickel-bis(dithiolene) complex remains within the polymer nanoparticles.

From these results, we can conclude that the NPs[Ni4C $\left.{ }_{12}\right]$ might be used for PTCR. Moreover, depending on the duration and the number of NIR irradiation, the speed of the drug release can be tuned according to the drug delivery needed for a specific therapy in term of quantity and duration. However, studies to optimize the system are still to be considered. Indeed, the rate of release can probably be further decreased, using lower irradiation powers.

In parallel, we have studied the in cellulo cytotoxicity of the $\mathrm{NPs}\left[\mathrm{Ni}_{4} \mathrm{C}_{12}\right]$ on two cell lines, the MDA-MB-231 and the HeLa cells, using 3-(4,5-dimethylthiazol-2-yl)-2,5-diphenyltetrazolium bromide (MTT) assays. As shown by Figure S11, the NPs[ $\left.\mathrm{Ni}_{4} \mathrm{C}_{12}\right]$ have a higher cytotoxicity on HeLa cells than on MDA-MB-231 cells. Indeed, we have observed a half maximal inhibitory concentration ( $\mathrm{IC}_{50}$, being the concentration at which 50\% of the cells were dead) around 300 $\mu \mathrm{g} / \mathrm{mL}$ in Hela cells, while, only a 80\% maximal inhibitory concentration ( IC $_{80}$ ) of $300 \mu \mathrm{g} / \mathrm{mL}$ was observed with the MDA-MB-231 cell line (Figure S11). To further investigate the impact of the presence of the $\mathrm{Ni}_{4} \mathrm{C}_{12}$ complexes and of the Dox combined or not with laser irradiation on the in vitro cytotoxicity, additional experiments have been performed on the more robust MDA-MB-231 cells.

The cell viabilities of the MDA-MB-231 cells incubated with empty NPs, free Dox, NPs[Dox], $\mathrm{NPs}\left[\mathrm{Ni}_{4} \mathrm{C}_{12}\right]$ and $\mathrm{NPs}\left[\mathrm{Ni}_{4} \mathrm{C}_{12}, \mathrm{Dox}\right]$ are presented in Figure 4 . These experiments have been performed at concentrations up to $100 \mu \mathrm{g} / \mathrm{mL}$ where the toxicity of the NPs remains negligible. First, comparison of the cells viability between the empty NPs and the NPs[Ni4C $\left.\mathrm{C}_{12}\right]$ without laser irradiation shows that the introduction of $10 \mathrm{wt} \%$ of $\mathrm{Ni}_{12}$ complexes inside the NPs does not induce additional toxicity since the cell viability was almost identical for all the tested 
concentrations. Moreover, the cells viability is not affected by the application of a laser irradiation in the absence of $\mathrm{Ni}_{4} \mathrm{C}_{12}$ complexes inside the NPs, meaning that the laser irradiation alone has no effect on the cell viability.

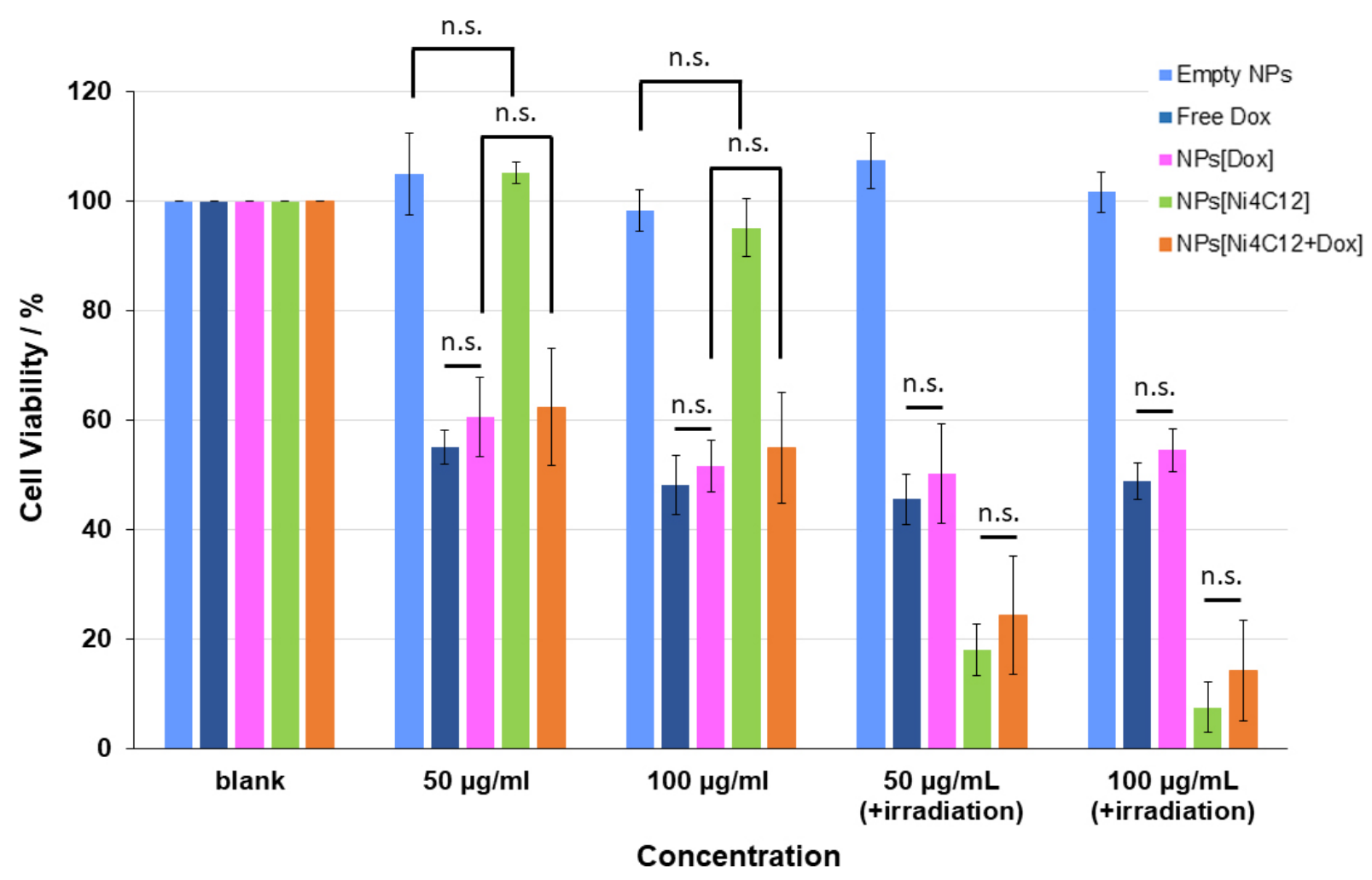

Figure 4. Relative cell viability of MDA-MB-231 cells incubated at 50 and $100 \mu \mathrm{g} / \mathrm{mL}$ of empty NPs NPs[Dox], NPs[Ni4C 12 ] and NPs[Ni4C ${ }_{12}$,Dox] without or with laser irradiation (5 min, 5 $W / \mathrm{cm}^{2}, 940 \mathrm{~nm}$ ). Free Dox was introduced at 2.5 and $5 \mu \mathrm{g} / \mathrm{mL}$ which corresponds to $5 \mathrm{w} \%$ of the NPs concentration. n.s.: non-significant. Statistical analyses were realized based on ANOVA Post Hoc Test (Tukey multiple comparisons of means or Wilcoxon rank sum test), only the non-significant values were marked on the figure for clarity's reasons.

Below $25 \mu \mathrm{g} / \mathrm{mL}$ of NPs[Dox] or equivalent $1.25 \mu \mathrm{g} / \mathrm{mL}$ of free dox, no significant effect have been detected on the cell viability. However, the cell viability drops to $80 \%$ at $25 \mu \mathrm{g} / \mathrm{mL}, 60$ $\%$ at $50 \mu \mathrm{g} / \mathrm{mL}$ and $50 \%$ at $100 \mu \mathrm{g} / \mathrm{mL}$ with the Dox loaded NPs. These results show that the Dox is likely naturally released from the NPs after one day of incubation and that Dox starts to be toxic at concentrations of $\mathrm{NPs}[\mathrm{Dox}]$ higher than $25 \mu \mathrm{g} / \mathrm{mL}$. Comparison of the results obtained on NPs[Dox] and equivalent quantities of free Dox shows that all the Dox has been 
release from the nanoparticles after one day incubation. Laser irradiation does not provide any additional effect.

In presence of $\mathrm{Ni}_{42} \mathrm{C}_{12}$ complexes, $\mathrm{NPs}\left[\mathrm{Ni}_{4} \mathrm{C}_{12}\right]$ or $\mathrm{NP}_{\mathrm{S}}\left[\mathrm{Ni}_{4} \mathrm{C}_{12}\right.$, Dox], higher cell death can be induced under laser irradiation above $50 \mu \mathrm{g} / \mathrm{mL}$. The cell viability after laser irradiation decreases from 60 to $20 \%$ at $50 \mu \mathrm{g} / \mathrm{mL}$ and from 50 to $15 \%$ at $100 \mu \mathrm{g} / \mathrm{mL}$. In absence of $\mathrm{Ni}_{4} \mathrm{C}_{12}$ complexes, laser irradiation does not affect the cell viability. The synergetic effect of the Dox and the laser irradiation is not noticeable. At this stage, based on the statistical analyses (Figure 4), there is no clear evidence of a potential cumulative effect of the presence of dox in addition to the already highly efficient photothermal effect induced by the presence of the Ni4C12 complex under laser irradiation. The strong cell death of the MDA-MB-231 cells upon laser irradiation in the presence of $\mathrm{NPs}\left[\mathrm{Ni}_{4} \mathrm{C}_{12}\right]$ was also confirmed by optical microscopy (Figure S12). The phase contrast observation of the cells was not markedly affected after incubation with $\mathrm{NPs}\left[\mathrm{Ni}_{4} \mathrm{C}_{12}\right]$ without irradiation whereas after irradiation, the cells adopted a round shape with loss of adherence, a sign of cell death. These last results clearly highlight the high potential of $\mathrm{NPs}\left[\mathrm{Ni}_{4} \mathrm{C}_{12}\right]$ to be used as efficient photothermal agents in addition to their photocontrolled drug release ability. The photothermal effect is effective above a concentration threshold of $50 \mu \mathrm{g} / \mathrm{mL}$ of $\mathrm{NPs}\left[\mathrm{Ni}_{4} \mathrm{C}_{12}\right.$ ], corresponding to a $\mathrm{Ni}_{42} \mathrm{C}_{12}$ concentration of $5 \mu \mathrm{g} / \mathrm{mL}$. Washing of the cell wells, prior to irradiation, have also revealed that no cell death can be induced under laser irradiation, meaning that the nanoparticles are not internalized inside the MDA-MB-231 cells (Figure S13). In this case, the cell death is only due to the presence of the Dox and not to the photothermal effect generated by $\mathrm{NPs}\left[\mathrm{Ni}_{4} \mathrm{C}_{12}\right]$ under laser irradiation. These results highlight that there is no need to internalize the nanoparticles inside the malignant cells to induce strong cell death by photothermal effect, i.e. a close proximity is sufficient.

\section{Conclusions}

We have demonstrated the possibility to co-encapsulate a NIR photothermal dye $\left(\mathrm{Ni}_{42} \mathrm{C}_{12}\right)$ and an anti-cancer drug (Dox) within nanoparticles based on biocompatible amphiphilic block copolymers ( $\mathrm{PEG}_{46}-b$-PMLABe 77 ). We have also proved that NIR irradiation of polymer nanoparticles containing nickel-bis(dithiolene) complexes allows for the fine control release of drugs in solution. The $\mathrm{Ni}_{42} \mathrm{C}_{12}$ and Dox loaded NPs have physico-chemical properties close to the ones of empty NPs, Dox loaded NPs or Ni4C 12 loaded NPs. The presence of the NIR sensitive dye has an influence on the Dox release upon NIR irradiation of the solution containing the NPs and on-demand drug delivery can also be achieved by applying short intermittent laser irradiation pulses. More importantly, cytotoxicity experiments have shown 
that the trapping of an hydrophobic nickel-bis(dithiolene) complex into the hydrophobic innercore of the NPs does not induce any additional toxicity to the NPs. In addition, above $50 \mu \mathrm{g} / \mathrm{mL}$, a clear photothermal effect can be observed under laser irradiation, showing that these nickelbis(dithiolene) complex loaded polymer nanoparticles can be good candidates to develop new agents for photothermal therapy.

Acknowledgements: The CNRS, the Ecole Nationale Supérieure de Chimie de Rennes and the University of Rennes 1 are gratefully acknowledged for financial support. The authors also gratefully acknowledge la Ligue Contre le Cancer Grand Ouest for financial support. JeanFrançois Bergamini is also gratefully acknowledged for his help in the TOC design. Xavier Le Goff is also gratefully acknowledged for the statistical analyses.

\section{References}

[1] D. Peer, J.M. Karp, S. Hong, O.C. Farokhzad, R. Margalit, R. Langer. “Nanocarriers as an emerging platform for cancer therapy.” Nature Nanotechnology, 2007, 2, 751-760. doi:10.1038/nnano.2007.387

[2] S. Shen, Y. Wu, Y. Liu, D. Wu. "High drug-loading nanomedicines: progress, current status, and prospects.” International Journal of Nanomedicine, 2017, 12, 4085-4109.

[3] G. Chen, I. Roy, C. Yang, P.N. Prasad. "Nanochemistry and Nanomedicine for Nanoparticle-based Diagnostics and Therapy.” Chemical Reviews, 2016, 116, 2826-2885. doi: 10.1021/acs.chemrev.5b00148.

[4] N. Singh, N. Tandan, S.P. Singh, S.P. Singh. "Nanoparticles as Drug Delivery System in Modern Trends.” Word Journal of Pharmacy and Pharmaceutical Sciences, 2016, 5(2), 11771193.

[5] M. Cagel, F.C. Tesan, E. Bernabeu, M.J. Salgueiro, M.B. Zubillaga, M.A. Moretton, D.A. Chiappetta. "Polymeric mixed micelles as nanomedicines: Achievements and perspectives.” European Journal of Pharmaceutics and Biopharmaceutics, 2017, 113, 211-228. doi: 10.1016/j.ejpb.2016.12.019.

[6] A. Gothwall, I. Khan, U. Gupta. "Polymeric Micelles: Recent Advancements in the Delivery of Anticancer Drugs.” Pharmaceutical Research, 2016, 33, 18-39. doi: 10.1007/s11095-0151784.

[7] X. Guo, L. Wang, X. Wei, S. Zhou. "Polymer-Based Drug Delivery Systems for Cancer Treatment.” Journal of Polymer Science, Part A: Polymer Chemistry, 2016, 54, 3525-3550. doi: 10.1002/pola.28252. 
[8] F.F. Davis. “The origin of pegnology.” Advance Drug Delivery Reviews, 2002, 54, 457458.

[9] K.K. Bawa, J.K. Oh. "Stimulus-Responsive Degradable Polylactide-Based Block Copolymer Nanoassemblies for Controlled/Enhanced Drug Delivery.” Molecular Pharmaceutics, 2017, 14, 2460-2474. doi: 10.1021/acs.molpharmaceut.7b00284.

[10] S. Cammas-Marion, P. Guérin. "Design of malolactonic acid esters with a large spectrum of specified pendant groups in the engineering of biofunctional and hydrolyzable polyesters.” Macromolecular Symposium, 2000, 153, 167-186. doi: 10.1002/1521-3900(200003)153:1.

[11] S. Cammas, M.M. Bear, A. Harada, P. Guérin, K. Kataoka. “New macromolecular micelles based on degradable amphiphilic block copolymers.” Macromolecular Chemistry and Physics, 2000, 201(3), 355-64. doi: 10.1002/(SICI)1521-3935(20000201)201:3.

[12] Z.W. Huang, V. Laurent, G. Chetouani, J.Y. Ljubimova, E. Holler, T. Benvegnu, P. Loyer, S. Cammas-Marion. "New functional degradable and bio-compatible nanoparticles based on poly(malic acid) derivatives for site-specific anti-cancer drug delivery.” International Journal of Pharmaceutics, 2012, 423, 83-92. doi:10.1016/j.ijpharm.2011.04.035.

[13] P. Loyer, W. Bedhouche, Z.W. Huang, S. Cammas-Marion. "Degradable and biocompatible nanoparticles decorated with cyclic RGD peptide for efficient drug delivery to hepatoma cells in vitro.” International Journal of Pharmaceutics, 2013, 454, 727-737. doi: 10.1016/j.ijpharm.2013.05.060.

[14] P. Loyer, S. Cammas-Marion. "Natural and synthetic poly(malic acid)-based derivates: A family of versatile biopolymers for the design of drug nanocarriers.” Journal of Drug Targeting, 2014, 22, 556-575. doi: 10.3109/1061186X.2014.936871.

[15] E. Vène, K. Jarnouen, Z.W. Huang, W. Bedhouche, T. Montier, S. Cammas-Marion, P. Loyer. "In vitro Toxicity Evaluation and in vivo Biodistribution of Polymeric Micelles Derived from Poly(ethylene glycol)-b-poly(benzyl malate) Copolymers.” Pharmaceutical Nanotechnology, 2016, 4(1), 24-37.

[16] V.P. Torchilin, Multifunctional nanocarriers. Adv. Drug Deliv. Rev., 2006, 58, 1532-1555. [17] J.H. Park, S. Lee, J.H. Kim, K. Park, K. Kim, I.C. Kwon, Polymeric nanomedicine for cancer therapy. Prog. Polym. Sci., 2008, 33, 113-137. doi:10.1016/j.progpolymsci.2007.09.003.

[18] A.S. Hoffman, The origins and evolution of "controlled" drug delivery systems. J. Control. Release, 2008, 132,153-163.

[19] B.D. Umery, L.S. Nair, C.T. Laurencin, Biomedical applications of biodegradable polymers. J. Polym. Sci. B: Polym. Phys., 2011, 49, 832-864. 
[20] S. Deshayes, A.M. Kasko, Polymeric biomaterials with engineered degradation. J. Polym. Sci., Part A: Polym. Chem., 2013, 51, 3531-3566. doi: 10.1002/pola.26765.

[21] H.G. Schil, Poly(N-isopropylacrylamide): experimental and application, Prog. Polymer Sci., 1992, 17, 163-249.

[22] M. van Dijk, T.M. Postma, D.T.S. Rijkers, R.M.J. Liskamp, C.F. van Nostrum, V.E. Hennink, Synthesis and characterization of tailorable biodegradable thermoresponsive methacryloylamide polymers based on L-serine and L-threonime alkyl esters, Polymer, 2010, 51, 2479-2485. doi: 10.1016/j.polymer.2010.04.010.

[23] C.L. Peng, Y.H. Shih, P.C. Lee, T.M.H. Hsieh, T.Y. Luo, M.J. Shieh. “Multimodal ImageGuided Photothermal Therapy Mediated by ${ }^{188}$ Re-Labeled Micelles Containing a CyanineType Photosensitizer.” ACS Nano, 2011, 5(7), 5594-5607. doi: 10.1021/nn201100m.

[24] Y. Hao, L. Wang, Y. Zhao, D. Meng, D. Li, H. Li, B. Zhang, J. Shi, H. Zhang, Z. Zhang, Y. Zhang. "Targeted Imaging and Chemo-Phototherapy of Brain Cancer by a Multifunctional Drug Delivery System.” Macromolecular Bioscience, 2015, 15, 1571-1585. doi: 10.1002/mabi.201500091.

[25] Y. Zhang, Z. Hou, Y. Ge, K. Deng, B. Liu, X. Li, Q. Li, Z. Cheng, P. Ma, C. Li, J. Lin. "DNA-Hybrid-Gated Photothermal Mesoporous Silica Nanoparticles for NIR-Responsive and Aptamer-Targeted Drug Delivery.” ACS Applied Materials \& Interfaces, 2015, 7, 2069620706. doi: 10.1021/acsami.5b05522.

[26] F. Kong, Z. Liang, D. Luan, X. Liu, K. Xu, B. Tang. “A Glutathione (GSH)-Responsive Near-Infrared (NIR) Theranostic Prodrug for Cancer Therapy and Imaging.” Analytical Chemistry, 2016, 88, 6450-6456. doi: 10.1021/acs.analchem.6b01135.

[27] M.A. Kim, S.D. Yoon, C.M. Lee. “A drug release system induced by near infrared laser using alginate microparticles containing melanin.” International Journal of Biological Macromolecules, 2017, 103, 839-844. doi: 10.1016/j.ijbiomac.2017.05.139.

[28] S.H. Kim, I. In, S.Y. Park. "pH-Responsive NIR-Absorbing Fluorescent Polydopamine with Hyaluronic Acid for Dual Targeting and Synergistic Effects of Photothermal and Chemotherapy.” Biomacromolecules, 2017, 18, 1825-1835. doi: 10.1021/acs.biomac.7b00267.

[29] G. Chen, R. Jaskula-Sztul, C.R. Esquibel, I. Lou, Q. Zheng, A. Dammalapati, A. Harrison, K.W. Eliceiri, W. Tang, H. Chen, S. Gong. "Neuroendocrine Tumor-Targeted Upconversion Nanoparticle-Based Micelles for Simultaneous NIRControlled Combination Chemotherapy and Photodynamic Therapy, and Fluorescence Imaging.” Advanced Functional Materials, 2017, 27, 1604671. doi: 10.1002/adfm.201604671. 
[30] J. Choia, E. Rustiqueb, M. Henrya, M. Guidettia, V. Josseranda, L. Sanceya, J. Boutetb, J.L. Colla. “Targeting tumors with cyclic RGD-conjugated lipid nanoparticles loaded with an IR780 NIR dye: In vitro and in vivo evaluation.” International Journal of Pharmaceutics, 2017, pii: S0378-5173(17)30175-8. doi: 10.1016/j.ijpharm.2017.03.007.

[31] A. Li, Y. Wang, T. Chen, W. Zhao, A. Zhang, S. Feng, J. Liu. "NIR-laser switched ICG/DOX loaded thermo-responsive polymeric capsule for chemo-photothermal targeted therapy.” European Polymer Journal, 2017, 92, 51-60. doi: 10.1016/j.eurpolymj.2017.04.019. [32] X. Zhang, N. Zhao, B. Wang, Z. Tian, Y. Dai, P. Ning, D. Chen. "Structure-inherent nearinfrared fluorescent probe mediates apoptosis imaging and targeted drug delivery in vivo.” Dyes and Pigments, 2017, 138, 204e212. doi: 10.1016/j.dyepig.2016.11.022.

[33] X.Q. Zhang, X. Xu, N. Bertrand, E. Pridgen, A. Swami, O.C. Farokhzad. "Interactions of nanomaterials and biological systems: Implication to personalized nanmedicine.” Advanced Drug Delivery Reviews, 2012, 64, 1363-1384. Doi: 10;1016/j.addr.2012.08.005.

[34] S. Shen, B. Ding, S. Zhang, X. Qi, K. Wang, J. Tian, Y. Yan, Y. Ge, L. Wu. "Near-infrared light-responsive nanoparticles with thermosensitive yolk-shell structure for multimodal imaging and chemo-photothermal therapy of tumor." Nanomedicine: Nanotechnology, Biology, and Medicine, 2017, 13, 1607-1616. 10.1016/j.nano.2017.02.014.

[35] C. Liu, Y. Zhang, M. Liu, Z. Chen, Y. Lin, W. Li, F. Cao, Z. Liu, J. Ren, X. Qu. “A NIRcontrolled cage mimicking system for hydrophobic drug mediated cancer therapy.” Biomaterials, 2017, 133, 208-218. doi: 10.1016/j.biomaterials.2017.04.032.

[36] R. Guo, Y. Tian, Y. Wang, W. Yang. "Near-Infrared Laser Triggered Nitric Oxide Nanogenerators for the Reversal of Multidrug Resistance in Cancer.” Advanced Functional Materials, 2017, 27, 16063898. Doi: 10.1002/adfm.201606398.

[37] C. Liu, Y. Zhang, M. Liu, Z. Chen, Y. Lin, W. Li, F. Cao, Z. Liu, J. Ren, X. Qu. “ A NIRcontrolled cage mimicking system for hydrophobic drug mediated cancer therapy.” Biomaterials, 2017, 139, 151-162. Doi: 10.1016/j.biomaterials.2017.06.008.

[38] C. Zheng, M. Zheng, P. Gong, D. Jia, P. Zhang, B. Shi, Z. Sheng, Y. Ma, L. Cai. "Indocyanine green-loaded biodegradable tumor targeting nanoprobes for in vitro and in vivo imaging.” Biomaterials, 2012, 33, 5603-5609. doi: 10.1016/j.biomaterials.2012.04.044.

[39] a) K.A. Wilk, K. Zielińska, J. Pietkiewicz, N. Skołucka, A. Choromańska, J. Rossowska, A. Garbiec, J. Saczko. "Photo-oxidative action in MCF-7 cancer cells induced by hydrophobic cyanines loaded in biodegradable microemulsion-templated nanocapsules.” Int. J. Oncol., 2012, 41, 105-116. doi: 10.3892/ijo.2012.1458; b) E. Engel, R. Schraml, T. Maisch, K. Kobuch, B. König R.M. Szeimies, J. Hillenkamp, W. Bäumler, R. Vasold. “Light-induced decomposition 
of indocyanine green” Invest Ophthalmol Vis Sci., 2008, 49(5), 1777-1783. doi: 10.1167/iovs.07-0911.

[40] Z. Sheng, D. Hu, M. Zheng, P. Zhao, H. Liu, D. Gao, P. Gong, G. Gao, P. Zhang, Y. Ma, L. Cai. "Smart Human Serum Albumin-Indocyanine Green Nanoparticles Generated by Programmed Assembly for Dual-Modal Imaging-Guided Cancer Synergistic Phototherapy.” ACS Nano, 2014, 8(12), 12310-12322. doi: 10.1021/nn5062386.

[41] S. Guha, S.K. Shaw, G.T. Spence, F.M. Roland, B.D. Smith. “Clean Photothermal Heating and Controlled Release from Near-Infrared Dye Doped Nanoparticles without Oxygen Photosensitization.” Langmuir, 2015, 31(28), 7826-7834. doi: 10.1021/acs.langmuir.5b01878. [42] K. Mebrouk, S. Debnath, M. Fourmigué, F. Camerel. "Photothermal Control of the Gelation Properties of Nickel Bis(dithiolene) Metallogelators under Near-Infrared Irradiation.” Langmuir, 2014, 30(28), 8592-8597. doi: 10.1021/la501826j.

[43] K. Mebrouk, F. Camerel, O. Jeannin, B. Heinrich, B. Donnio, M. Fourmigué. "High Photothermal Activity within Neutral Nickel Dithiolene Complexes Derived from Imidazolium-Based Ionic Liquids.” Inorganic Chemistry, 2016, 55(3), 1296-1303. doi: 10.1021/acs.inorgchem.5b02648.

[44] M. Ciancone, F. Camerel. "Laser triggered phase transition in photothermal liquid crystals.” Chem. Commun., 2017, 53, 6339-6342. Doi: 10.1039/C7CC03318D.

[45] K. Mebrouk, F. Chotard, C. Le Goff-Gaillard, Y. Arlot-Bonnemains, M. Fourmigué, F. Camerel. "Water-soluble nickel-bis(dithiolene) complexes as photothermal agents.” Chemical Communications, 2015, 51, 5268-5270. doi: 10.1039/C4CC08231A.

[46] K. Mebrouk, T. Vives, S. Cammas-Marion, T. Benvegnu, C. Le Goff-Gaillard, Y. ArlotBonnemains, M. Fourmigué, F. Camerel. "Fine and Clean Photothermally-Controlled NIR Drug Delivery from Biocompatible Nickel-bis(dithiolene) Containing Liposomes.” ChemMedChem, 2017, 12, 1753-1758. doi: 10.1002/cmdc.201700344.

[47] S. Cammas, I. Renard, V. Langlois, Ph. Guérin. "Poly(b-malic acid): obtaining of high molecular weights by improvement of the synthesis route.” Polymer, 1996, 37, 4215-4220.

[48] R. Perochon, L. Piekara-Sady, W. Jurga, R. Clérac, Marc Fourmigué. “Amphiphilic paramagnetic neutral gold dithiolene complexes.” Dalton Transactions, Royal Society of Chemistry, 2009, 3052-3061. doi:10.1039/b820819k.

[49] O. Thioune, H. Fessi, J.P. Devissaguet, F. Puisieux. "Preparation of pseudolatex by nanoprecipitation: influence of the solvent nature on intrinsic viscosity and interaction constant.” International Journal of Pharmaceutics, 1997, 146, 233-238. doi: 10.1016/S03785173(96)04830-2 
[50] T. Mosmann. "Rapid colorimetric assay for cellular growth and survival: application to proliferation and cytotoxicity assays.” Journal of lmmunological Methods, 1983, 65, 55-63. doi: 10.1016/0022-1759(83)90303-4.

[51] D.K. Roper, W. Ahn, M. Hoepfner. "Microscale Heat Transfer Transduced by Surface Plasmon Resonant Gold Nanoparticles.” Journal of Physical Chemistry C, 2007, 111(9), 3636-3641. doi: 10.1021/jp064341w. 

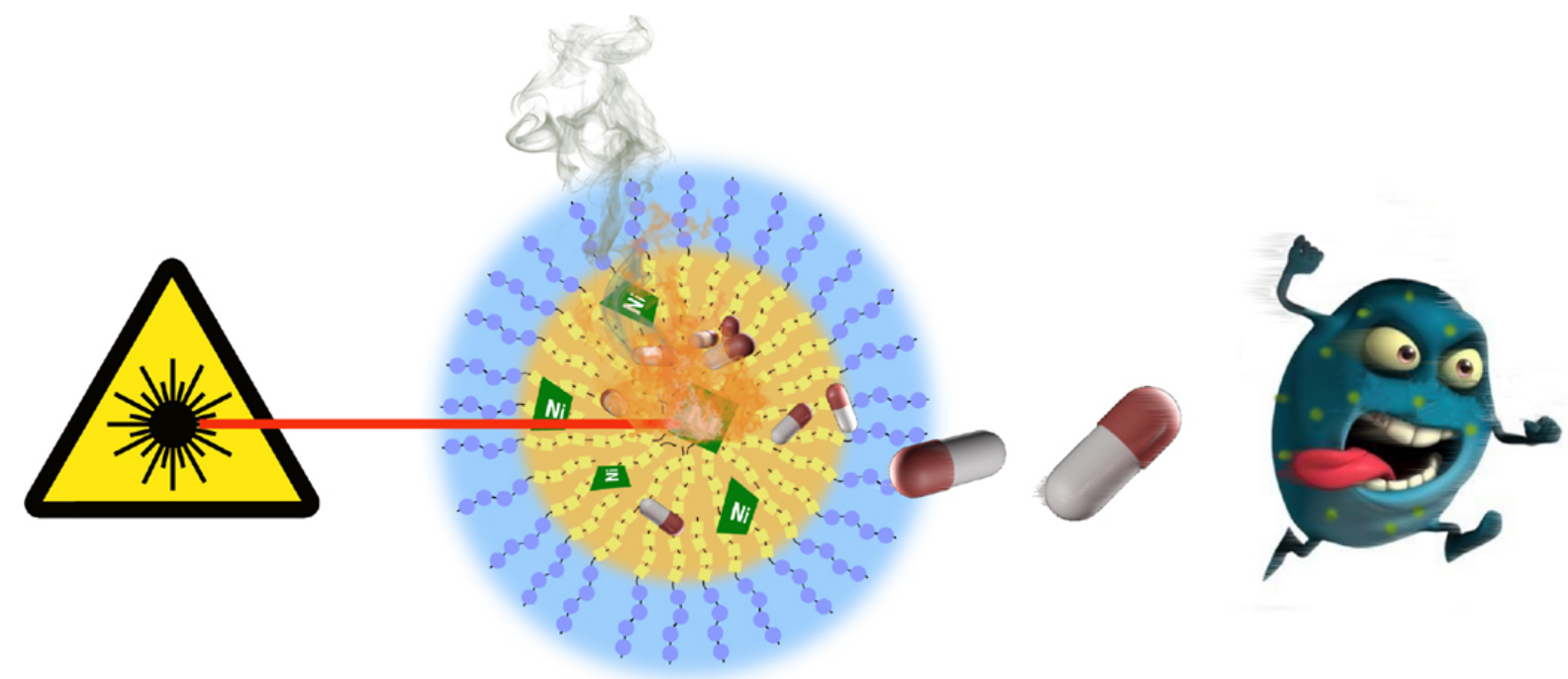

Encapsulation of photoactive nickel-bis(dithiolene) complexes into biocompatible and biodegradable block copolymers nanoparticles allows for the fine controlled release of their drug content and photothermal therapy under NIR laser irradiation. 